\title{
Article \\ Phenylalanine, Tyrosine, and DOPA Are bona fide Substrates for Bambusa oldhamii BoPAL4
}

\author{
Chun-Yen Hsieh ${ }^{1}$, Yi-Hao Huang ${ }^{2}$, Hui-Hsuan Yeh ${ }^{2}$, Pei-Yu Hong ${ }^{2}$, Che-Jen Hsiao ${ }^{3}$ and Lu-Sheng Hsieh ${ }^{2, *(D)}$ \\ 1 Department of Pathology and Laboratory Medicine, Shin Kong Wu Ho-Su Memorial Hospital, No. 95, \\ Wen Chang Road, Shih Lin District, Taipei City 111, Taiwan; t012874@ms.skh.org.tw \\ 2 Department of Food Science, Tunghai University, No. 1727, Sec. 4, Taiwan Boulevard, Xitun District, \\ Taichung 40704, Taiwan; g09621001@thu.edu.tw (Y.-H.H.); s07620217@thu.edu.tw (H.-H.Y.); \\ g08621018@thu.edu.tw (P.-Y.H.) \\ 3 Department of Ecology and Conservation Biology, Texas A\&M University, 2126 TAMU, \\ College Station, TX 77843, USA; hsiaob@tamu.edu \\ * Correspondence: 1shsieh@thu.edu.tw; Tel.: +886-4-23590121 (ext. 37331)
}

Citation: Hsieh, C.-Y.; Huang, Y.-H.; Yeh, H.-H.; Hong, P.-Y.; Hsiao, C.-J.;

Hsieh, L.-S. Phenylalanine, Tyrosine, and DOPA Are bona fide Substrates for Bambusa oldhamii BoPAL4. Catalysts 2021, 11, 1263. https://doi.org/ $10.3390 /$ catal11111263

Academic Editor:

Roberto Fernandez-Lafuente

Received: 30 September 2021

Accepted: 19 October 2021

Published: 20 October 2021

Publisher's Note: MDPI stays neutral with regard to jurisdictional claims in published maps and institutional affiliations.

Copyright: (c) 2021 by the authors. Licensee MDPI, Basel, Switzerland. This article is an open access article distributed under the terms and conditions of the Creative Commons Attribution (CC BY) license (https:// creativecommons.org/licenses/by/ $4.0 /)$.

\begin{abstract}
Phenylalanine ammonia-lyase (PAL) links the plant primary and secondary metabolisms, and its product, trans-cinnamic acid, is derived into thousands of diverse phenylpropanoids. Bambusa oldhamii BoPAL4 has broad substrate specificity using L-phenylalanine, L-tyrosine, and L-3,4dihydroxy phenylalanine (L-DOPA) as substrates to yield trans-cinnamic acid, $p$-coumaric acid, and caffeic acid, respectively. The optimum reaction $\mathrm{pH}$ of BoPAL4 for three substrates was measured at 9.0, 8.5, and 9.0, respectively. The optimum reaction temperatures of BoPAL4 for three substrates were obtained at 50,60 , and $40{ }^{\circ} \mathrm{C}$, respectively. The $\mathrm{Km}$ values of BoPAL4 for three substrates were 2084, 98, and $956 \mu \mathrm{M}$, respectively. The $k_{\text {cat }}$ values of BoPAL4 for three substrates were 1.44, 0.18 , and $0.06 \sigma^{-1}$, respectively. The major substrate specificity site mutant, BoPAL4-H123F, showed better affinity toward L-phenylalanine by decreasing its $K_{\mathrm{m}}$ value to $640 \mu \mathrm{M}$ and increasing its $k_{\text {cat }}$ value to $1.87 \mathrm{~s}^{-1}$. In comparison to wild-type BoPAL4, the specific activities of BoPAL4-H123F using L-tyrosine and L-DOPA as substrates retained $5.4 \%$ and $17.8 \%$ residual activities. Therefore, L-phenylalanine, L-tyrosine, and L-DOPA are bona fide substrates for BoPAL4.
\end{abstract}

Keywords: Bambusa oldhamii; phenylalanine ammonia-lyase; phenylalanine/tyrosine ammonia-lyase; substrate specificity; plant secondary metabolism; phenylpropanoid

\section{Introduction}

Phenylalanine ammonia-lyase (PAL, EC 4.3.1.24) is the enzyme that catalyzes the first committed step of general phenylpropanoid pathways in plants, catalyzing the conversion of L-phenylalanine (L-Phe) to trans-cinnamic acid via a non-oxidative deamination reaction (Scheme 1) [1-3]. Trans-cinnamic acid served as the start point of secondary metabolism is then hydroxylated by a membrane-bounded cinnamate 4-hydroxylase (C4H, EC 1.14.14.91) to yield $p$-coumaric acid [4] for the synthesis of thousands of phenylpropanoids $[5,6]$. Plant hormone, salicylic acid, is also synthesized via the PAL-mediated pathway [7]. PAL activity is elevated by light treatment, maintaining phenolic compound levels in fresh-cut sweet peppers [8]. Trans-cinnamic acid and $p$-coumaric acid have been shown to exert multifarious health benefits for humans, including anti-diabetic, anti-obesity, anti-oxidant, and anti-microbial activities [9,10]. P-coumaric acid is further hydroxylated by 4-coumarate 3-hydroxylase (4CMH or $\mathrm{C} 3 \mathrm{H}, \mathrm{EC}$ 1.14.14.9) to yield caffeic acid, an intermediate involved in the early stage of lignin biosynthesis [11]. In humans, caffeic acid provides numerous beneficial biological activities, including anti-oxidant and anti-microbial activities [12-14]. 


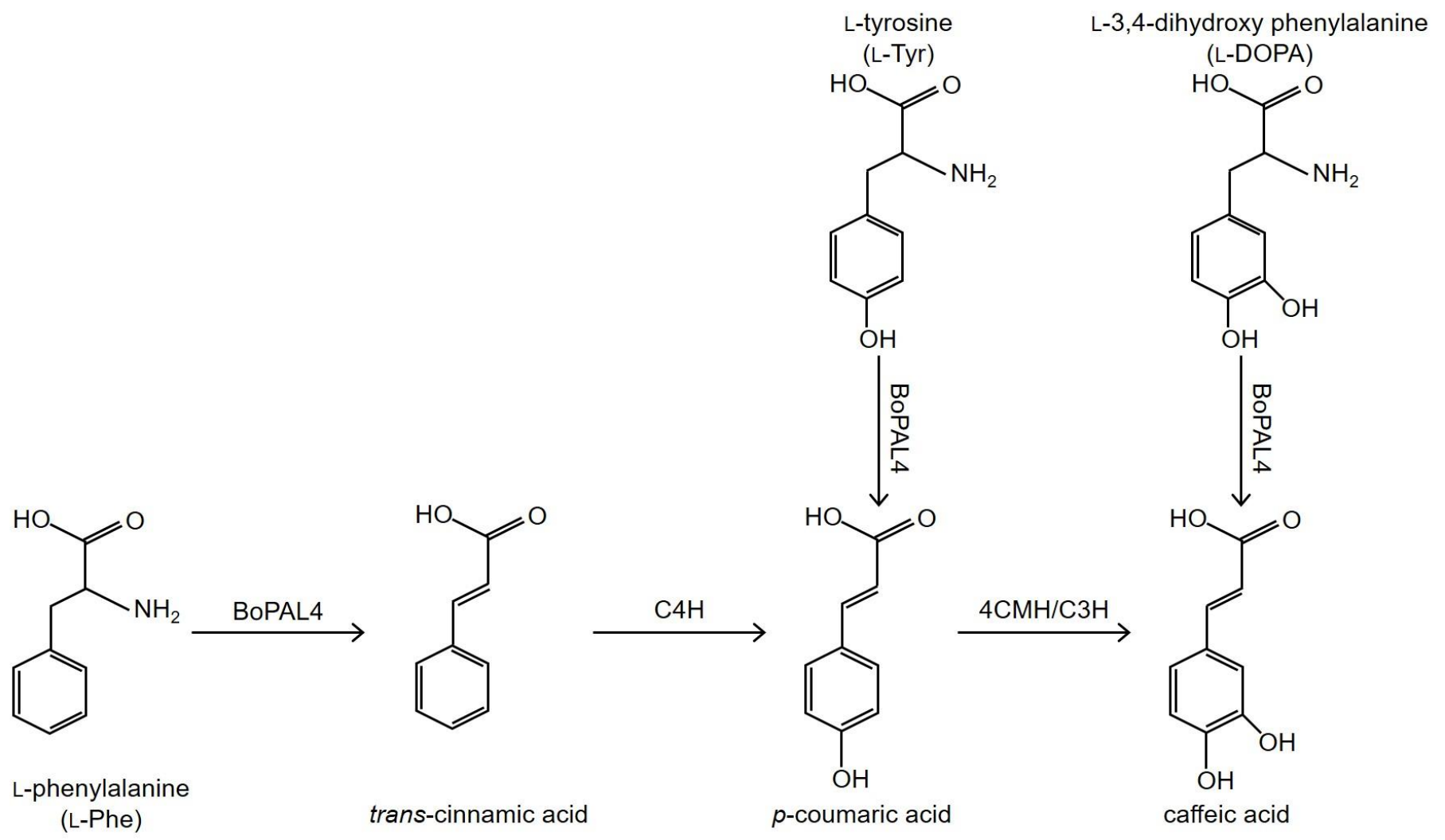

Scheme 1. The enzyme reaction catalyzed by the bamboo BoPAL4 phenyl alanine/tyrosine ammonia-lyase (PTAL). BoPAL4 PTAL catalyzes the non-oxidative deamination of L-phenylalanine to yield trans-cinnamic acid for the synthesis of $p$ coumaric acid via the enzyme reaction catalyzed by the $\mathrm{C} 4 \mathrm{H}$ cinnamate 4-hydroxylase. BoPAL4 PTAL can bypass the $\mathrm{BoC} 4 \mathrm{H}$ requirement to produce $p$-coumaric acid by the deamination of L-tyrosine. In plants, $p$-coumaric acid is hydroxylated at C-3 position to yield 3,4,-dihydroxy trans-cinnamic acid, also known as caffeic acid, by the 4CMH/C3H 4-coumarate 3-hydroxylase. BoPAL4 PTAL can also bypass the $4 \mathrm{CMH}$ requirement to produce caffeic acid by the deamination of L-3,4,-dihydroxy phenylalanine (L-DOPA).

Histidine ammonia-lyase (HAL, EC 4.3.1.3) [15], PAL, and tyrosine ammonia-lyase (TAL, EC 4.3.1.24) share the conserved active site motif, Ala-Ser-Gly, which can spontaneously merge into a 4-methylidine-imidazol-5-one (MIO) group [16,17]. PAL is one of the highly post-translational modified enzymes in plant secondary metabolism [18]. The degradation of PAL is mediated by ubiquitin proteasome system [19,20]. PAL is a phosphoprotein [21-23], and the phosphorylation site identified in French bean is the Thr-545 residue in a conserved R/K-X-X-S/T motif [24]. PAL proteins generally function as tetrameric enzymes [25-27].

In dicot plants, PAL exclusively uses L-Phe as substrate [28-30]; however, several PAL isoforms discovered in monocot plants exhibit dual functions using both L-Phe and L-tyrosine (L-Tyr) as substrates for the synthesis of trans-cinnamic acid and $p$-coumaric acid, respectively (Scheme 1) [27,31,32]. Therefore, the bifunctional PAL is renamed as phenylalanine/tyrosine ammonia-lyase (PTAL, EC 4.3.1.25) [32-34]. Unlike PALs, specific tyrosine ammonia-lyase (TAL, EC 4.3.1.24) solely occurs in some microorganisms [35-39]. Hence, the detectable TAL activity in monocot plants is contributed by the PTAL bifunctional enzyme $[29,40]$, accounting for half lignin biosynthesis in grass plants $[33,41]$.

Rhodobacter sphaeroides TAL (RsTAL) enzyme is firstly utilized as a model to investigate the substrate specificity between L-Phe and L-Tyr; two independent studies reveal that His-89 of RsTAL is the major substrate specificity switch site [36,42]. Bambusa oldhamii BoPAL1 is only specific to L-Phe but not to L-Tyr; site-directed mutagenesis studies have demonstrated that TAL activities are detectable in the BoPAL1-F133H and BoPAL1-V197I mutants $[27,32]$. Sorghum bicolor SbPAL1 is also a PTAL enzyme, utilizing L-Phe and L-Tyr 
as substrates (Scheme 1) [34]. In addition, SbPAL1 exhibits L-3,4-dihydroxy phenylalanine (L-DOPA) ammonia-lyase (DAL) activity to convert L-DOPA to caffeic acid [34]. TAL activities are completely eliminated in RsTAL-H89F [36] and SbPAL1-H123F mutants [34]. Taken together, Phe or His residue at the substrate specificity switch site is critical for PAL or TAL activity, respectively.

Bamboo PAL proteins are encoded by a multi-gene family, namely, BoPAL1 [43], BoPAL2 [26], BoPAL3, and BoPAL4 [27]. The substrate specificity site of BoPAL1, BoPAL2, or BoPAL3 is a Phe residue, whereas an His residue is present in the BoPAL4 protein (Figure 1A) [27]. BoPAL4 exhibits both PAL and TAL activities [27], making it a good candidate for studying substrate specificity. In the present study, a site-directed mutagenesis combined with PAL/TAL/DAL activities analysis toward diverse substrates, L-Phe/L-Tyr/L-DOPA, was carried out to better understand the catalytic functions in the BoPAL4. Furthermore, the optimum reaction conditions of BoPAL4 using three substrates were examined.

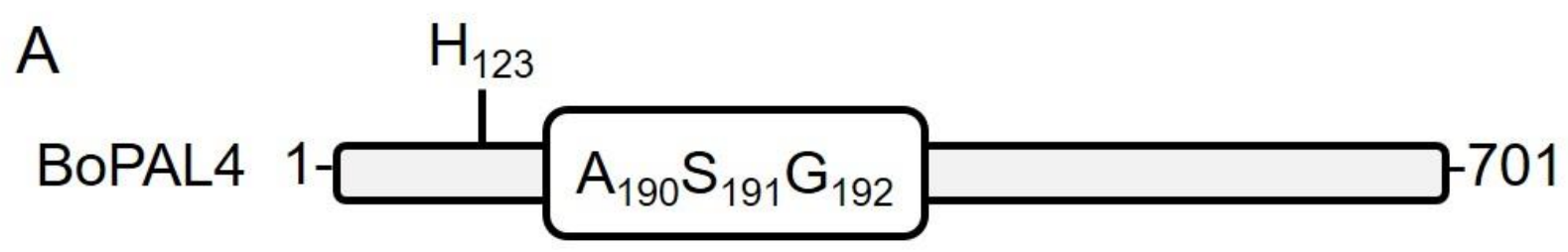

B

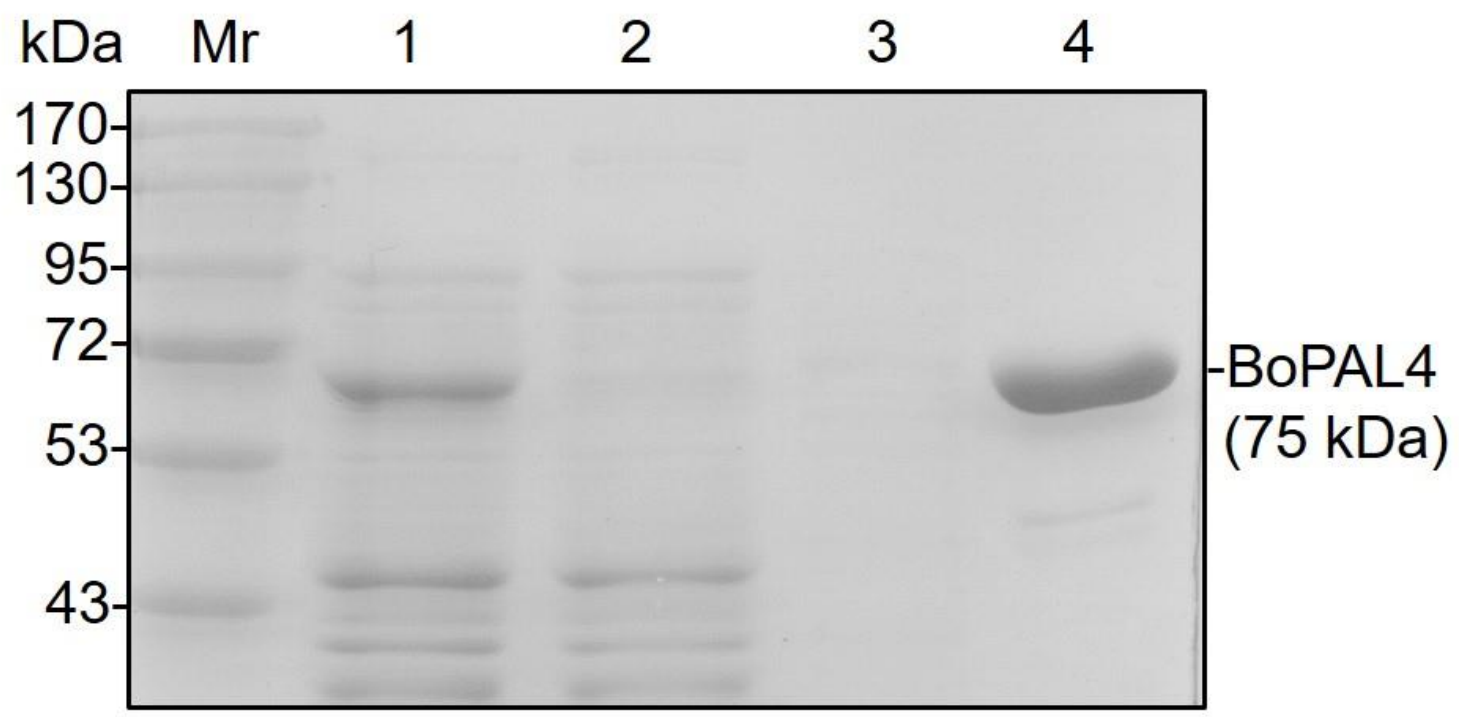

\section{0\% SDS-gel, Coomassie staining}

Figure 1. Expression and purification of recombinant BoPAL4 in Escherichia coli. (A) The primary structure of the BoPAL4 is illustrated. BoPAL4 is a 701-a.a protein with the conserved Ala-Ser-Gly catalytic motif as well as the substrate specificity site at His-123. (B) Recombinant BoPAL4 protein was purified using Ni-NTA affinity chromatography and separated using $10 \%$ SDS-PAGE and then stained with Coomassie Blue. Mr, molecular weight SDS-PAGE marker; lane 1, crude extract; lane 2, unbound protein; lane 3, flow-through; lane 4, $125 \mathrm{mM}$ imidazole-buffer-eluted BoPAL4.

\section{Results}

\subsection{Expression and Purification of Recombinant BoPAL4 in Escherichia coli}

BoPAL4 contained a 2106 bp open-reading frame (ORF) and encoded a 701- amino acids polypeptide (Figure 1A). The Ala-Ser-Gly catalytic motifs of BoPAL4 and SbPAL1 [34] are from 190 to 192 and from 189 to 191, respectively. Coincidentally, the substrate specificity 
switch site of both proteins is located at His-123 (Figure 1A). To better understand the catalytic function of BoPAL4, the coding region of BoPAL4 was inserted into pTrcHisA plasmid and expressed heterologously in the E. coli Top10 strain (Table 1). N-terminal $\mathrm{His}_{6}$-tag was fused to the recombinant BoPAL4 protein for facilitating affinity purification by the Ni-NTA resin (Figure 1B). The recombinant BoPAL4 protein was highly expressed and mainly eluted at $125 \mathrm{mM}$ imidazole buffer (Figure 1B, lane 4). On the SDS-gel, a nearly homogeneous protein band with a molecular mass of $75 \mathrm{kDa}$ corresponded to the predicted molecular mass of BoPAL4 protein. Thus, E. coli expression system was useful for producing recombinant BoPAL4 protein.

Table 1. Bacterial strain and plasmids used for recombinant protein expressions.

\begin{tabular}{|c|c|c|}
\hline Strain & Relevant Characteristics & Source or Ref. \\
\hline E. coli Top10 & $\begin{array}{l}\mathrm{F}^{-} \text {mcrA } \Delta(\text { mrr-hsdRMS-mcrBC) } \varphi 80 \text { lacZ } \Delta \mathrm{M} 15 \Delta l a c \mathrm{X} 74 \text { recA1 } \\
\left.\text { araD139 } \Delta(\text { ara-leu }) 7697 \text { galU galK } \lambda^{-} \text {rpsL(Str }{ }^{\mathrm{R}}\right) \text { end } \mathrm{A} 1 \text { nup } \mathrm{G}\end{array}$ & Invitrogen \\
\hline Plasmid & Relevant Characteristics & Source or Ref. \\
\hline pTrcHisA & E. coli expression vector with $\mathrm{N}$-terminal $\mathrm{His}_{6}$-tag fusion & Invitrogen \\
\hline pTrcHisA-BoPAL4 & BoPAL4 coding sequence inserted into pTrcHisA & [27] \\
\hline pTrcHisA-BoPAL4-H123F & Point mutation H123F derivative of pTrcHisA-BoPAL4 & This study \\
\hline
\end{tabular}

\subsection{Optimum $\mathrm{pH}$ and Temperature for PAL, TAL and DAL Activities of BoPAL4}

To examine if BoPAL4 can use L-Phe, L-Tyr, and L-DOPA as substrates, PAL, TAL, and DAL activities were performed with $12.1 \mathrm{mM}$ L-Phe, $1.9 \mathrm{mM}$ L-Tyr, and $10 \mathrm{mM}$ L-DOPA in a range of temperatures between 25 and $80^{\circ} \mathrm{C}$ (Figure 2A). The maximum/optimum PAL, TAL, and DAL activities of BoPAL4 were measured at 50, 60, and $40^{\circ} \mathrm{C}$, similar to the optimum temperatures of BoPAL1 and BoPAL2 (Table 2) [26,43]. Accordingly, PAL, $\mathrm{TAL}$, and DAL activities were performed with standard assay conditions in a range of $\mathrm{pH}$ between 5 and 11 (Figure 2B). The maximum/optimum PAL, TAL, and DAL activities of BoPAL4 were measured at $\mathrm{pH} 9.0,8.5$, and $9.0^{\circ} \mathrm{C}$, also similar to the optimum temperatures of BoPAL1 and BoPAL2 (Table 2) [26,43]. Therefore, L-Phe, L-Tyr, and L-DOPA were bona fide substrates for BoPAL4 PTAL.

A

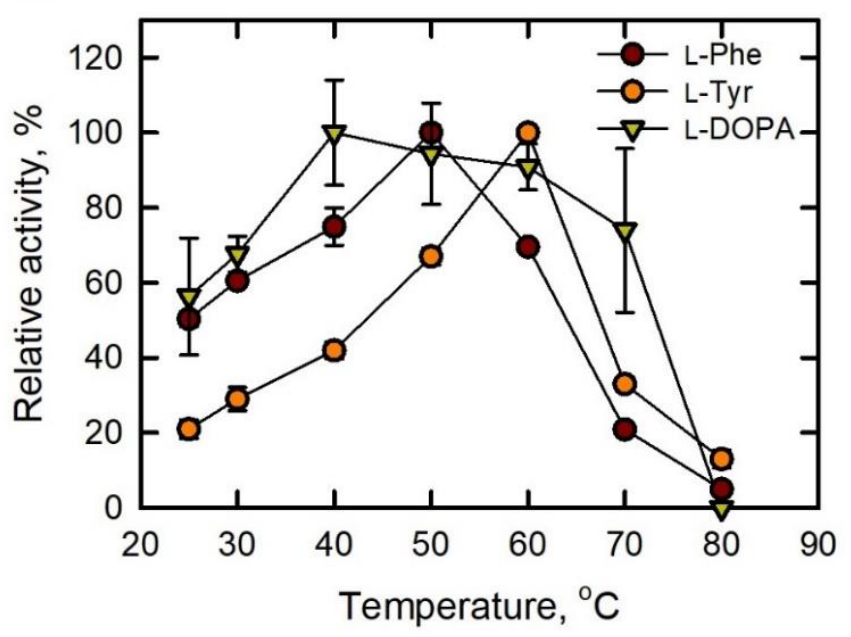

B

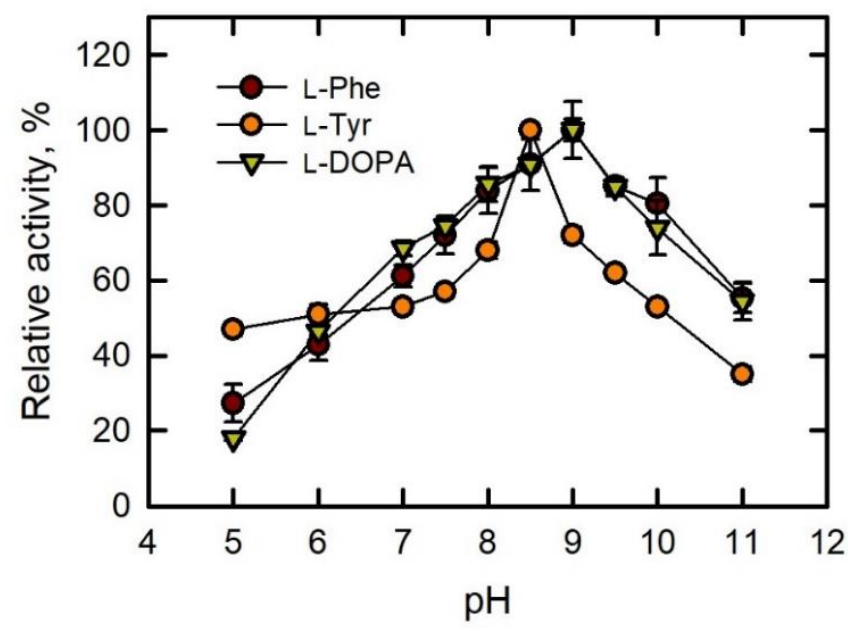

Figure 2. Optimum $\mathrm{pH}$ and temperature of PAL, TAL, and DAL activities for BoPAL4 PTAL. (A) Optimum temperatures of BoPAL4 using L-Phe $(\bullet)$, L-Tyr $(\bullet)$, or L-DOPA $(\nabla)$ as substrate. Activities were measured under standard assay conditions in a range of temperatures from 25 to $80^{\circ} \mathrm{C}$. (B) Optimum pH of BoPAL4 using L-Phe $(\bullet)$, L-Tyr $(\bullet)$, and L-DOPA $(\nabla)$ as substrates. Activities were measured under standard assay conditions in a range of $\mathrm{pH}$ from 5 to 11 . All experiments were performed in triplicate and expressed as average \pm standard deviation (S.D., error bars). 
Table 2. Comparison of biochemical properties and kinetic parameters of E. coli expressed BoPAL proteins.

\begin{tabular}{|c|c|c|c|c|c|c|}
\hline Protein & Substrate $^{1}$ & Optimum pH & $\begin{array}{l}\text { Optimum } \\
\text { Temp }\left({ }^{\circ} \mathrm{C}\right)\end{array}$ & $k_{\text {cat }}\left(\mathrm{s}^{-1}\right)$ & $K_{\mathrm{m}}(\mu \mathrm{M})$ & $k_{\mathrm{cat}} / K_{\mathrm{m}}\left(\mathrm{s}^{-1} \mu \mathrm{M}^{-1}\right)$ \\
\hline \multirow{3}{*}{ BoPAL4 } & L-Phe & 9.0 & 50 & 1.44 & 2084 & $6.9 \times 10^{-4}$ \\
\hline & L-Tyr & 8.5 & 60 & 0.18 & 98 & $18.4 \times 10^{-4}$ \\
\hline & L-DOPA & 9.0 & 40 & 0.06 & 956 & $0.6 \times 10^{-4}$ \\
\hline BoPAL4-H123F & L-Phe & 9.0 & 50 & 1.87 & 640 & $29.2 \times 10^{-4}$ \\
\hline
\end{tabular}

${ }^{1}$ L-Phe, phenylalanine; L-Tyr, tyrosine; and L-DOPA, 3,4-dihydroxy-phenylalanine.

\subsection{Kinetic Parameters for PAL, TAL, and DAL Activities of BoPAL4}

The kinetic parameters of BoPAL4 using L-Phe as substrate were measured with its PAL activity. Hyperbolic saturation curve (Figure 3A) and double reciprocal plot (Figure 3B) were obtained to calculate the kinetic parameters. The $K_{\mathrm{m}}$ value of BoPAL4 for L-Phe was estimated as $2084 \mu \mathrm{M}$, higher than the values of BoPAL1 $(230 \mu \mathrm{M})$ [43], BoPAL2 $(333 \mu \mathrm{M})$ [27], and SbPAL1 $(340 \mu \mathrm{M})$ [34]. The kinetic parameters of BoPAL4 using L-Tyr as substrate were measured with its TAL activity. Hyperbolic saturation curve (Figure 3C) and double reciprocal plot (Figure 3D) were obtained to calculate the kinetic parameters. The $K_{\mathrm{m}}$ and $k_{\text {cat }}$ values of BoPAL4 for L-Tyr were estimated as $98 \mu \mathrm{M}$ and $0.18 \mathrm{~s}^{-1}$, respectively. The kinetic parameters of BoPAL4 using L-DOPA as substrate were measured with its DAL activity. Hyperbolic saturation curve (Figure 3E) and double reciprocal plot (Figure 3F) were obtained to calculate the kinetic parameters. The $K_{\mathrm{m}}$ value of BoPAL4 for L-DOPA was estimated as $956 \mu \mathrm{M}$, which was 2.4-fold higher than SbPAL1 (0.40 mM) [34]. Taken together, BoPAL proteins were highly active at about $50{ }^{\circ} \mathrm{C}$ in alkaline reaction conditions.
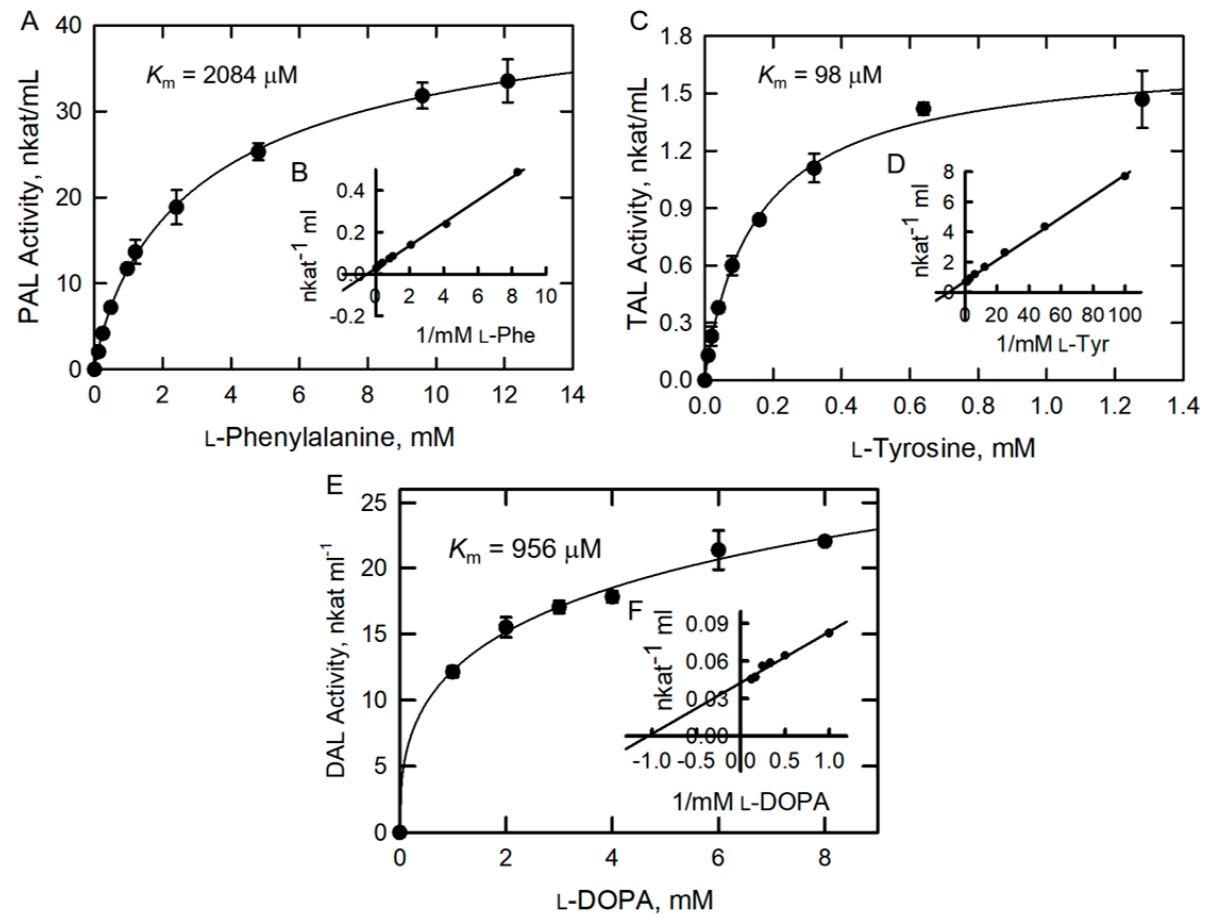

Figure 3. Kinetic parameters of BoPAL4 PTAL. To determine kinetic parameters using L-Phe as substrate, substrate saturation curve (A) and Lineweaver-Burk double reciprocal plot (B) of the initial rate result of BoPAL4 were used. To determine kinetic parameters using L-Tyr as substrate, substrate saturation curve (C) and Lineweaver-Burk double reciprocal plot (D) of the initial rate result of BoPAL4 were used. To determine kinetic parameters using L-DOPA as substrate, substrate saturation curve (E) and Lineweaver-Burk double reciprocal plot (F) of the initial rate result of BoPAL4 were used. All experiments were performed in triplicate and expressed as average \pm standard deviation (S.D., error bars). 


\subsection{Kinetic Parameters for PAL Activity of BoPAL4-H123F}

His-123 is the predicted substrate specificity switch site in the BoPAL4 (Figure 1A). Accordingly, site-directed mutant protein BoPAL4-H123F (Table 1) was also expressed and purified in the E. coli Top10 strain under the same procedure of BoPAL4 expression. After affinity purification, the purities of the $125 \mathrm{mM}$ imidazole-buffer-eluted wild-type (WT) BoPAL4 and BoPAL4-H123F proteins were migrated at the same position on the SDS-gel (Figure 4A). The expression level of BoPAL4-H123F was comparable to that of BoPAL4, indicating that $E$. coli expression system is also useful for producing BoPAL4-H123F protein.

A

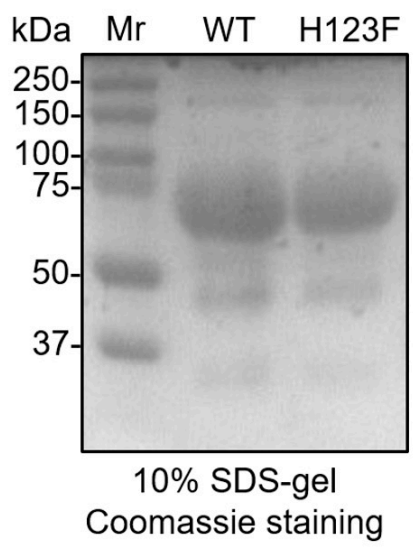

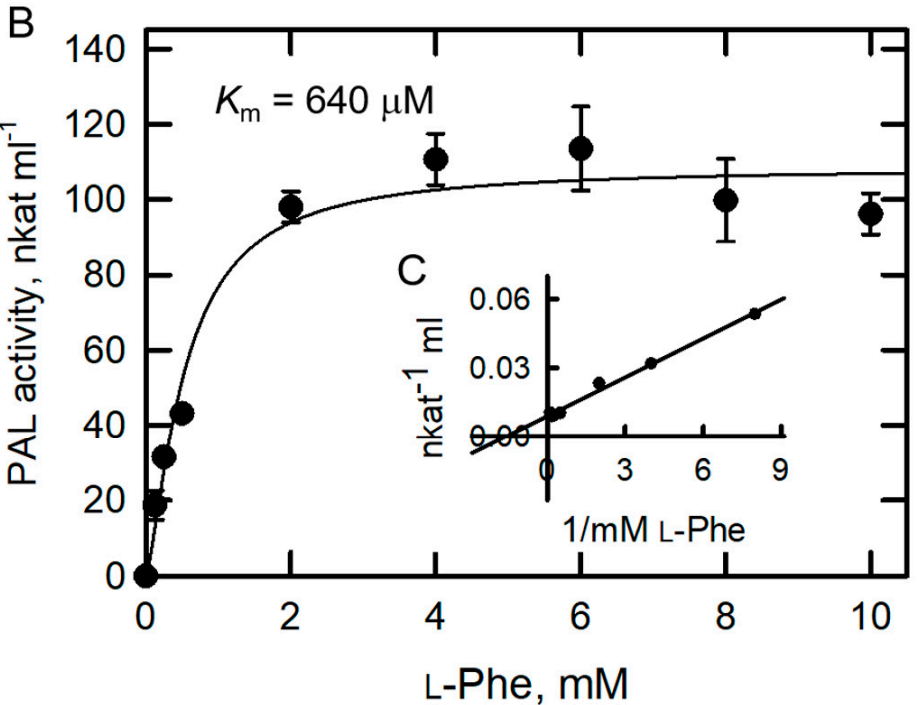

Figure 4. Kinetic parameters of BoPAL4-H123F. (A) BoPAL4-WT and BoPAL4-H123F were expressed and purified in E. coli. The $125 \mathrm{mM}$ imidazole eluted fractions were separated using 10\% SDS-PAGE and then stained with Coomassie Blue. Mr, molecular weight SDS-PAGE marker. To determine kinetic parameters using L-Phe as substrate, substrate saturation curve (B) and Lineweaver-Burk double reciprocal plot (C) of the initial rate result of BoPAL4-H123F were used. All experiments were performed in triplicate and expressed as average \pm standard deviation (S.D., error bars).

The kinetic parameters of BoPAL4-H123F using L-Phe as substrate were measured its PAL activity. Hyperbolic saturation curve (Figure 4B) and double reciprocal plot (Figure 4C) were obtained to calculate the kinetic parameters. The $K_{\mathrm{m}}$ and $k_{\text {cat }}$ values of BoPAL4-H123F for L-Phe were estimated as $640 \mu \mathrm{M}$ and $1.87 \mathrm{~s}^{-1}$, respectively (Table 2). The overall catalytic properties ( $k_{\text {cat }} / K_{\mathrm{m}}$ value) of BoPAL4-H123F using L-Phe as substrate were 4.2-fold higher than that of wild-type BoPAL4.

TAL and DAL activities were significantly decreased in the BoPAL4-H123F. By using L-Tyr and L-DOPA as substrates, kinetic parameters of BoPAL4-H123F are not readily obtained, presumably due to their miniature TAL and DAL activities. Therefore, PAL-, TAL-, and DAL-specific activities were compared instead between WT and mutant proteins.

\subsection{Comparison of Specific Activities in Wild-Type BoPAL4 and BoPAL4-H123F Mutants}

The $K_{\mathrm{m}}$ value of BoPAL4-H123F using L-Phe $(640 \mu \mathrm{M})$ was lower than that of BoPAL4 $(2084 \mu \mathrm{M})$, indicating that BoPAL4-H123F mutant protein increases the binding affinity toward its substrate L-Phe. Likewise, the specific PAL activity of BoPAL4-H123F was slightly higher (1.3-fold) than that of BoPAL4 (Figure 5A). Unlike this, the specific TAL and DAL activities only retained $7.5 \%$ (Figure $5 \mathrm{~B}$ ) and $17.8 \%$ (Figure $5 \mathrm{C}$ ) in comparison with wild-type BoPAL4. Taken together, His-123 of BoPAL4 is the major specificity switch site for using L-Tyr and L-DOPA as substrates. 

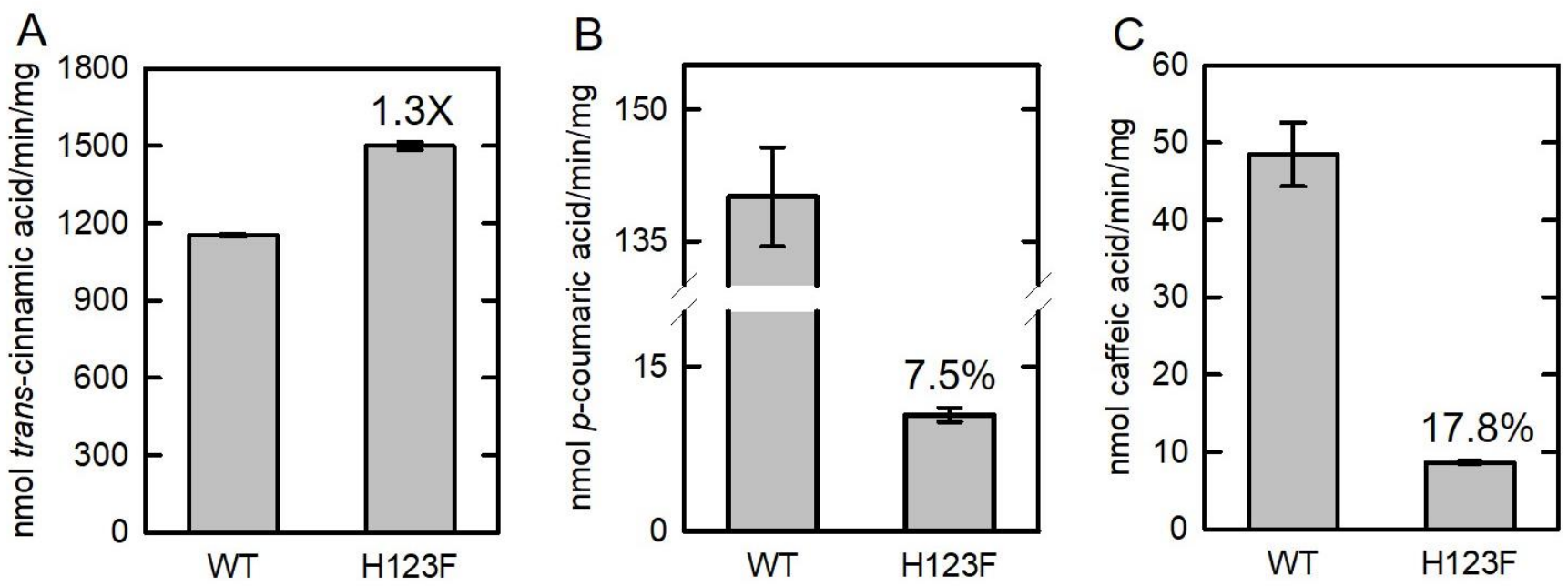

Figure 5. Comparison of specific activities in the BoPAL4 and BoPAL4-H123F proteins. PAL (A)-, TAL (B)-, and DAL (C)-specific activities of BoPAL4 and BoPAL4-H123F were measured under standard assay conditions. All experiments were performed in triplicate and expressed as average \pm standard deviation (S.D., error bars).

\section{Discussion}

Green bamboo BoPAL4 is a multifunctional enzyme, catalyzing the nonoxidative deamination of L-Phe, L-Tyr, and L-DOPA to yield trans-cinnamic acid, $p$-coumaric acid, and caffeic acid, respectively. The $K_{\mathrm{m}}$ value of L-Phe in the BoPAL4-H123F significantly decreases, indicating that His-123 is the major substrate specificity switch site. Phe-123 to His mutation of BoPAL4 exhibits higher L-Phe binding affinity than wild-type BoPAL4 as well as an elevated $k_{\text {cat }}$ value of $1.87 \mathrm{~s}^{-1}$. On the contrary, the TAL and DAL activities are significantly reduced in BoPAL4-H123F, which further confirms that the His-123 of BoPAL4 is essential for utilizing L-Tyr and L-DOPA as substrates. Two studies have shown that TAL activities are completely abolished in both RsTAL-H89F and SbPAL1-H123F mutants $[34,36]$. To our knowledge, L-DOPA utilization has never been studied in those mutants. Our results show that BoPAL4-H123F still can monitor TAL and DAL activities to some degree. Site-directed mutagenesis study can be performed in the BoPAL4-H123F to further identify more substrate specificity site (s).

Trans-cinnamic acid derivatives are shown to have useful effects in human health, such as anti-obesity and anti-microbial activities [9,10]. Recently, several studies have successfully immobilized PAL proteins on different carriers [44-47]. Electrospun nanofibers combined with dextran polyaldehyde crosslinker are suitable for BoPAL1 and BoPAL2 immobilization [47]. In this study, we showed that BoPAL4 had broad substrate specificities for synthesizing at least three products. In the meantime, other putative aromatic substrates are being tested to see if they can be utilized by the BoPAL4 enzyme. Furthermore, immobilization of BoPAL4 on electrospun nanofibers has great potential for the synthesis of aromatic compounds.

\section{Materials and Methods}

\subsection{Reagents}

Bio-Rad protein assay dye reagent concentrate [48], Nuvia ${ }^{\mathrm{TM}}$ IMAC resin, and general chemicals for protein electrophoresis were purchased from Bio-Rad, Hercules, CA, USA. Restriction endonuclease enzymes, DNA proofreading polymerase, PrimeStar, and T4 DNA ligase for molecular biology manipulations were obtained from Takara, Kusatsu, Shiga, Japan. Plasmid mini-preparation kit and gel extraction/PCR cleanup kit were from Geneaid Biotech, New Taipei City, Taiwan. Oligonucleotide synthesis and DNA sequencing were serviced by Tri-I Biotech, New Taipei City, Taiwan. L-phenylalanine, L-tyrosine, L-DOPA, trans-cinnamic acid, $p$-coumaric acid, and caffeic acid were purchased 
from MilliporeSigma, Burlington, MA, USA. All other chemicals and reagents were ACS grade or higher.

\subsection{Bacterial Strains, Plasmids Construction, Site-Directed Mutagenesis, and Bacterial Growth Conditions}

E. coli strain and plasmids used in this study are listed in Table 1. Top10 strain was utilized for propagation of plasmids and for the induction of recombinant proteins. Plasmid pTrcHisA-BoPAL4 and pTrcHisA-BoPAL4-H123F directed the expression of N-terminal His $_{6}$-tagged wild-type BoPAL4 [27] and BoPAL4-H123F mutant protein, respectively. The pTrcHisA-BoPAL4-H123F plasmid containing an His to Phe point mutation was generated by QuikChange ${ }^{\circledR}$ site-directed mutagenesis (Strategene, Agilent, Santa Clara, CA, USA) as described by Hsieh et al. 2020 [32]. PCR product was obtained by PrimeStar DNA polymerase, and mixture was digested by $D p n$ I restriction endonuclease overnight and transformed chemically into Top10 component cells followed by DNA sequencing.

E. coli Top10 cells carrying BoPAL4 wild-type and mutant plasmids were grown at $37{ }^{\circ} \mathrm{C}$ in Luria-Bertani medium $(1 \%$ tryptone, $0.5 \%$ yeast extract, $1 \% \mathrm{NaCl}$, and $\mathrm{pH}$ 7.0) supplemented with $100 \mathrm{mg} / \mathrm{mL}$ ampicillin. The expression of BoPAL4 proteins was induced at $30^{\circ} \mathrm{C}$ with $1 \mathrm{mM}$ isopropyl- $\beta$-D-thiogalactoside (IPTG) for $6-8 \mathrm{~h}$ [27]. Cells were centrifuged at $6000 \times g$ for $10 \mathrm{~min}$, and pellets were stored at $-20^{\circ} \mathrm{C}$ freezer before use.

\subsection{Preparations of BoPAL4 Enzymes}

E. coli cells that expressed $\mathrm{His}_{6}$-tagged BoPAL proteins were freshly collected or resuspended from $-20{ }^{\circ} \mathrm{C}$ freezer, disrupting by sonication using a Branson cell disruptor $[32,49,50]$. Proteins were purified from cell lysates by affinity chromatography with Nuvia ${ }^{\mathrm{TM}}$ Ni-NTA resin. Samples were fractioned and eluted by varied concentrations of imidazole. Protein content of each step of the preparation was measured at $A_{595} \mathrm{~nm}$ using a microplate reader (BioTek 800TS, Winooski, VT, USA), and bovine serum albumin (BSA) was served as reference. All purification procedures were conducted at $4{ }^{\circ} \mathrm{C}$ cold room.

\subsection{Sodium Dodecyl Sulfate-Polyacrylamide Gel Electrophoresis}

Purified BoPAL4 proteins were analyzed by polyacrylamide gel electrophoresis (PAGE) using a Mini-PROTEAN Tetra Cell system (Bio-Rad, Hercules, CA, USA). Proteins were stained by Coomassie Brilliant Blue R-250 and destained by $20 \%$ methanol solution. Gel image was obtained by a Gel Doc XR+ Imaging System (Bio-Rad, Hercules, CA, USA)

\subsection{PAL Activity Assay}

Phenylalanine ammonia-lyase activity was measured by following the formation of trans-cinnamic acid as the absorbance varied at $290 \mathrm{~nm}$ [32] using trans-cinnamic acid as standard. The reaction mixture for PAL contained $50 \mathrm{mM}$ Tris- $\mathrm{HCl}(\mathrm{pH} 8.5), 12.1 \mathrm{mM}$ L-Phe, and an aliquot amount of BoPAL4 enzyme in a total volume of $1.0 \mathrm{~mL}$. The reaction was incubated at $37^{\circ} \mathrm{C}$ for $30 \mathrm{~min}$ and ceased by adding $100 \mu \mathrm{L} 6 \mathrm{~N} \mathrm{HCl}$. PAL activity was defined as nkat (nanomole of trans-cinnamic acid formed per second).

\subsection{TAL Activity Assay}

Tyrosine ammonia-lyase activity was measured by following the formation of $p$ coumaric acid as the absorbance varied at $310 \mathrm{~nm}$ [32] using $p$-coumaric acid as standard. The reaction mixture for TAL contained $50 \mathrm{mM}$ Tris- $\mathrm{HCl}(\mathrm{pH}$ 8.5), $1.9 \mathrm{mM} \mathrm{L-Tyr}$, and an aliquot amount of BoPAL enzyme in a total volume of $1.0 \mathrm{~mL}$. The reaction was incubated at $37^{\circ} \mathrm{C}$ for $30 \mathrm{~min}$ and ceased when $100 \mu \mathrm{L} 6 \mathrm{~N} \mathrm{HCl}$ was added. TAL activity was defined as nkat (nanomole of $p$-coumaric acid formed per second).

\subsection{DAL Activity Assay}

DOPA ammonia-lyase activity was measured by following the formation of caffeic acid as the absorbance varied at $350 \mathrm{~nm}$ [34] using caffeic acid as standard. The reaction 
mixture for DAL contained $50 \mathrm{mM}$ Tris- $\mathrm{HCl}$ (pH 8.5), $10 \mathrm{mM}$ L-DOPA, and an aliquot amount of BoPAL enzyme in a total volume of $1.0 \mathrm{~mL}$. The reaction was incubated at $37^{\circ} \mathrm{C}$ for $30 \mathrm{~min}$ and ceased when $100 \mu \mathrm{L} 6 \mathrm{~N} \mathrm{HCl}$ was added. DAL activity was defined as nkat (nanomole of caffeic acid formed per second).

\subsection{Biochemical Properties and Enzyme Kinetic}

To determine the optimum reaction $\mathrm{pH}$, activity assays were performed at standard reaction mixture using various $\mathrm{pH}$ universal buffers. To obtain the optimum reaction temperature, activity assays were carried out at standard reaction mixture using in various temperatures.

To determine the kinetic parameter for PAL, TAL, and DAL, a range of concentration of L-Phe, L-Tyr, and L-DOPA was varied from 0 to $12.1 \mathrm{mM}$, from 0 to $1.28 \mathrm{mM}$, and from 0 to $10 \mathrm{mM}$, respectively. Substrate saturation curves were carried out after $10 \mathrm{~min}$ incubation [32,51] based on Michaelis-Menten equation [52], adapting to double reciprocal plot [53] for the calculation of the $K_{\mathrm{m}}$ and $k_{\text {cat }}$ values.

Author Contributions: Methodology, C.-Y.H., Y.-H.H., P.-Y.H., H.-H.Y. and L.-S.H. Software, C.-Y.H. and L.-S.H. Validation, C.-J.H. and L.-S.H. Formal analysis, C.-Y.H. and L.-S.H. Resources, L.-S.H. Data curation, L.-S.H. Writing - original draft preparation, C.-Y.H., C.-J.H., and L.-S.H. Supervision, project administration, and funding acquisition, L.-S.H. All authors have read and agreed to the published version of the manuscript.

Funding: This study was supported in part or in total by research grants from the Ministry of Science and Technology, Taiwan (MOST 110-2313-B-029-001-MY3 to LSH) and from the Shin Kong Wu Ho-Su Memorial Hospital (2021SKHAND008 to CYH), Taipei, Taiwan.

Data Availability Statement: Data are contained in the main article.

Conflicts of Interest: The authors declare no conflict of interest.

\section{References}

1. Koukol, J.; Conn, E.E. Metabolism of aromatic compounds in higher plants. IV. Purification and properties of phenylalanine deaminase of Hordeum vulgare. J. Biol. Chem. 1961, 236, 2692-2698. [CrossRef]

2. Zhang, X.; Liu, C.J. Multifaceted regulations of gateway enzyme phenylalanine ammonia-lyase in the biosynthesis of phenylpropanoids. Mol. Plant 2015, 8, 17-27. [CrossRef] [PubMed]

3. Deng, Y.; Shanfa, L. Biosynthesis and regulation of phenylpropanoids in plants. Crit. Rev. Plant Sci. 2017, 36, 257-290. [CrossRef]

4. Bell-Lelong, D.A.; Cusumano, J.C.; Meyer, K.; Chapple, C. Cinnamate 4-hydroxylase expression in Arabidopsis. Regulation in response to development and the environment. Plant Physiol. 1997, 113, 729-738. [CrossRef]

5. Achnine, L.; Blancaflor, E.B.; Rasmussen, S.; Dixon, R.A. Colocalization of L-phenylalanine ammonia-lyase and cinnamate 4-hydroxylase for metabolic channeling in phenylpropanoids biosynthesis. Plant Cell 2004, 16, 3098-3109. [CrossRef] [PubMed]

6. Chen, O.; Deng, L.; Ruan, C.; Yi, L.; Zeng, K. Pichia galeiformis induced resistance in postharvest citrus by activating the phenylpropanoid biosynthesis pathway. J. Agri. Food Chem. 2021, 69, 2619-2631. [CrossRef] [PubMed]

7. Zhang, K.; Lu, J.; Li, J.; Yu, Y.; Zhang, J.; He, Z.; Ismail, O.M.; Wu, J.; Xie, X.; Li, X.; et al. Efficiency of chitosan application against Phytophthora infestans and the activation of defence mechanisms in potato. Int. J. Biol. Macromol. 2021, 182, 1670-1680. [CrossRef]

8. Maroga, G.M.; Soundy, P.; Sivakumar, D. Different postharvest responses of fresh-cut sweet peppers related to quality and antioxidant and phenylalanine ammonia lyase activities during exposure to light-emitting diode treatment. Foods 2019 , 8, 359. [CrossRef]

9. Mitani, T.; Ota, K.; Inaba, N.; Kishida, K.; Koyama, H.A. Antimicrobial activity of the phenolic compounds of Prunus mume against enterobacteria. Biol. Pharm. Bull. 2018, 41, 208-212. [CrossRef]

10. Wang, Z.; Ge, S.; Li, S.; Lin, H.; Lin, S. Anti-obesity effect of trans-cinnamic acid on HepG2 cells and HFD-fed mice. Food Chem. Toxicol. 2020, 137, 111148. [CrossRef]

11. Barros, J.; Escamilla-Trevino, L.; Song, L.; Rao, X.; Serrani-Yarce, J.C.; Palacios, M.D.; Engle, N.; Choudhury, F.K.; Tschalinski, T.J.; Venables, B.J.; et al. 4-Coumarate 3-hydroxylase in the lignin biosynthesis pathway is a cytosolic ascorbate peroxidase. Nat. Commun. 2019, 10, 1994. [CrossRef]

12. Abdallah, F.B.; Fetoui, H.; Fakhfakh, F.; Keskes, L. Caffeic acid and quercetin protect erythrocytes against the oxidative stress and the genotoxic effects of lambda-cyhalothrin in vitro. Hum. Exp. Toxicol. 2012, 31, 92-100. [CrossRef]

13. Lima, V.N.; Oliveira-Tintino, C.D.M.; Santos, E.S.; Morais, L.P.; Tintino, S.R.; Freitas, T.S.; Geraldo, Y.S.; Pereira, R.L.S.; Cruz, R.P.; Menezes, I.R.A.; et al. Antimicrobial and enhancement of the antibiotic activity by phenolic compounds: Gallic acid, caffeic acid and pyrogallol. Microb. Pathog. 2016, 99, 56-61. [CrossRef] [PubMed] 
14. Shull, T.E.; Kurepa, J.; Miller, R.D.; Martinez-Ochoa, N.; Smalle, J.A. Inhibition of Fusarium oxysporum f. sp. nicotianae growth by phenylpropanoid pathway intermediates. Plant Pathol. J. 2020, 36, 637-642. [CrossRef] [PubMed]

15. Schwede, T.F.; Rétey, J.; Schulz, G.E. Crystal structure of histidine ammonia-lyase revealing a novel polypeptide modification as the catalytic electrophile. Biochemistry 1999, 38, 5355-5361. [CrossRef] [PubMed]

16. Rétey, J. Discovery and role of methylidene imidazolone, a highly electrophilic prosthetic group. Biochim. Biophys. Acta. 2003, 1647, 179-184. [CrossRef]

17. Ritter, H.; Schulz, G.E. Structural basis for the entrance into the phenylpropanoid metabolism catalyzes by phenylalanine ammonia-lyase. Plant Cell 2004, 16, 3426-3436. [CrossRef] [PubMed]

18. Sulis, D.; Wang, J.P. Regulation of lignin biosynthesis by post-translational protein modifications. Front Plant Sci. 2020, 11, 914. [CrossRef] [PubMed]

19. Zhang, X.; Gou, M.; Liu, C.-J. Arabidopsis Kelch repeat F-box proteins regulate phenylpropanoid biosynthesis via controlling the turnover of phenylalanine ammonia-lyase. Plant Cell 2013, 25, 4994-5010. [CrossRef]

20. Yu, H.; Li, D.; Yang, D.; Xue, Z.; Li, J.; Xing, B.; Yan, K.; Han, R.; Liang, Z. SmKFB5 protein regulates phenolic acid biosynthesis by controlling the degradation the degradation of phenylalanine ammonia-lyase in Salvia miltiorrhiza. J. Exp. Bot. 2021, 72, 4915-4929. [CrossRef]

21. Bolwell, G.P. A role for phosphorylation in the down-regulation of phenylalanine ammonia-lyase in suspension-cultured cells of French bean. Phytochemistry 1992, 31, 4081-4086. [CrossRef]

22. Cheng, S.H.; Sheen, J.; Gerrish, C.; Bolwell, G.P. Molecular identification of phenylalanine ammonia-lyase as a substrate of a specific constitutively active Arabidopsis CDPK expressed in maize protoplasts. FEBS Lett. 2001, 503, 185-188. [CrossRef]

23. Allwood, E.G.; Davies, D.R.; Gerrish, C.; Bolwell, G.P. Regulation of CDPKs, including identification of PAL kinase, in biotically stressed cells of French bean. Plant Mol. Biol. 2002, 49, 533-544. [CrossRef]

24. Allwood, E.G.; Davies, D.R.; Gerrish, C.; Ellis, B.E.; Bolwell, G.P. Phosphorylation of phenylalanine ammonia-lyase: Evidence for a novel protein kinase and identification of the phosphorylated residue. FEBS Lett. 1999, 457, 47-52. [CrossRef]

25. Reichert, A.I.; He, X.Z.; Dixon, R.A. Phenylalanine ammonia-lyase (PAL) from tobacco (Nicotiana tabacum): Characterization of the four tobacco PAL genes and active heterotetrameric enzymes. Biochem. J. 2009, 424, 233-242. [CrossRef]

26. Hsieh, L.-S.; Yeh, C.-S.; Cheng, C.-Y.; Yang, C.-C.; Lee, P.-D. Cloning and expression of a phenylalanine ammonia-lyase gene (BoPAL2) from Bambusa oldhamii in Escherichia coli and Pichia pastoris. Protein Expr. Purif. 2010, 71, 224-230. [CrossRef]

27. Hsieh, L.-S.; Ma, G.-J.; Yang, C.-C.; Lee, P.-D. Cloning, expression, site-directed mutagenesis and immunolocalization of phenylalanine ammonia-lyase in Bambusa oldhamii. Phytochemistry 2010, 71, 1999-2009. [CrossRef]

28. Appert, C.; Logemann, E.; Hahlbrock, K.; Schmid, J.; Amrhein, N. Structural and catalytic properties of the four phenylalanine ammonia-lyases from parsley (Petroselinum crispum Nym). Eur. J. Biochem. 1994, 225, 2177-2185. [CrossRef] [PubMed]

29. Barros, J.; Dixon, R.A. Plant phenylalanine/tyrosine ammonia-lyases. Trends Plant Sci. 2020, 25, 66-79. [CrossRef] [PubMed]

30. Moisă, M.E.; Amariei, D.A.; Nagy, E.Z.A.; Szarvas, N.; Toșa, M.I.; Paizs, C.; Bencze, L.C. Fluorescent enzyme-coupled activity assay for phenylalanine ammonia-lyases. Sci. Rep. 2020, 10, 18418. [CrossRef] [PubMed]

31. Rösler, J.; Krekel, F.; Amrhein, N.; Schmid, J. Maize phenylalanine ammonia lyase has tyrosine ammonia-lyase activity. Plant Physiol. 1997, 113, 175-179. [CrossRef]

32. Hsieh, C.-Y.; Huang, Y.-H.; Lin, Z.-Y.; Hsieh, L.-S. Insights into the substrate selectivity of Bambusa oldhamii phenylalanine ammonia-lyase 1 and 2 through mutational analysis. Phytochem. Lett. 2020, 38, 140-143. [CrossRef]

33. Barros, J.; Serrani-Yarce, J.C.; Chen, F.; Baxter, D.; Venables, B.J.; Dixon, R.A. Role of bifunctional ammonia-lyase in grass cell wall biosynthesis. Nat. Plants 2016, 2, 16050. [CrossRef]

34. Jun, S.Y.; Sattler, S.A.; Cortez, G.S.; Vermerris, W.; Sattler, S.E.; Kang, C. Biochemical and structural analysis of substrate specificity of a phenylalanine ammonia-lyase. Plant Physiol. 2018, 176, 1452-1468. [CrossRef] [PubMed]

35. Kyndt, J.A.; Meyer, T.E.; Cusanovich, M.A.; Van Beeumen, J.J. Characterization of a bacterial tyrosine ammonia lyase, a biosynthetic enzyme for the photoactive yellow protein. FEBS Lett. 2002, 512, 240-244. [CrossRef]

36. Louie, G.V.; Bowman, M.E.; Moffitt, M.C.; Baiga, T.J.; Moore, B.S.; Noel, N.P. Structural determinants and modulation of substrate specificity in phenylalanine-tyrosine ammonia-lyase. Chem. Biol. 2006, 13, 1327-1338. [CrossRef] [PubMed]

37. Moffitt, M.C.; Louie, G.V.; Bowman, M.E.; Pence, J.; Noel, J.P.; Moore, B.S. Discovery of two cyanobacterial phenylalanine ammonia-lyases: Kinetic and structural characterization. Biochemistry 2008, 46, 1004-1012. [CrossRef]

38. Jendresen, C.B.; Stahlhut, S.G.; Li, M.; Gasper, P.; Siedler, S.; Förster, J.; Maury, J.; Borodina, I.; Nielsen, A.T. Highly active and specific tyrosine ammonia-lyases from diverse origins enable enhanced production of aromatic compounds in bacteria and Saccharomyces cerevisiae. Appl. Environ. Microbiol. 2015, 81, 4458-4476. [CrossRef] [PubMed]

39. MacDonald, M.C.; Arivalagan, P.; Barre, D.E.; Maclnnis, J.A.; D'Cunha, G.B. Rhodotorula glutinis phenylalanine/tyrosine ammonia lyase enzyme catalyzed synthesis of the methyl ester of para-hydroxycinnamic acid and its potential antibacterial activity. Front Microbiol. 2016, 7, 281. [CrossRef]

40. Feduraev, P.; Skrypnik, L.; Riabova, A.; Pungin, A.; Tokupova, E.; Maslennikov, P.; Chupakhina, G. Phenylalanine and tyrosine as exogenous precursors of wheat (Triticum aestivum L.) secondary metabolism through PAL-associate pathways. Plants $2020,9,476$. [CrossRef]

41. Maeda, E.A. Lignin biosynthesis: Tyrosine shortcut in grasses. Nat. Plants 2016, 2, 16080. [CrossRef] [PubMed] 
42. Watts, K.T.; Mijts, B.N.; Lee, P.C.; Manning, A.J.; Schmidt-Dannert, C. Discovery of a substrate selectivity switch in tyrosine ammonia-lyase, a member of the aromatic amino acid lyase family. Chem. Biol. 2006, 13, 1317-1326. [CrossRef] [PubMed]

43. Hsieh, L.-S.; Hsieh, Y.-L.; Yeh, C.-S.; Cheng, C.-Y.; Yang, C.-C.; Lee, P.-D. Molecular characterization of a phenylalanine ammonialyase gene (BoPAL1) from Bambusa oldhamii. Mol. Biol. Rep. 2011, 38, 283-290. [CrossRef] [PubMed]

44. Cui, J.; Zhao, Y.; Feng, Y.; Lin, T.; Zhong, C.; Tan, Z.; Jia, S. Encapsulation of spherical cross-linked phenylalanine ammonia lyase aggregates in mesoporous biosilica. J. Agri. Food Chem. 2017, 65, 618-625. [CrossRef] [PubMed]

45. Cui, J.; Zhao, Y.; Tan, Z.; Zhong, C.; Han, P.; Jia, S. Mesoporous phenylalanine ammonia lyase microspheres with improved stability through calcium carbonate templating. Int. J. Biol. Macromol. 2017, 98, 887-896. [CrossRef]

46. Boros, K.; Moisă, M.E.; Nagy, C.L.; Paizs, C.; Toşa, M.I.; Bencze, L.C. Robust, site-specificity immobilized phenylalanine ammonia-lyases for the enantioselective ammonia addition of cinnamic acids. Catal. Sci. Technol. 2021, 11, 5553. [CrossRef]

47. Hong, P.-Y.; Huang, Y.-H.; Lim, G.C.W.; Chen, Y.-P.; Hsiao, C.-J.; Chen, L.-H.; Ciou, J.-Y.; Hsieh, L.-S. Production of trans-cinnamic acid by immobilization of the Bambusa oldhamii BoPAL1 and BoPAL2 phenylalanine ammonia-lyases on electrospun nanofibers. Int. J. Mol. Sci. 2021, 22, 11184. [CrossRef]

48. Bradford, M.M. A rapid and sensitive method for the quantitation of microgram quantities of protein utilizing the principle of protein dye-binding. Anal. Biochem. 1976, 72, 248-254. [CrossRef]

49. Hsiao, C.-J.; Hsieh, C.-Y.; Hsieh, L.-S. Cloning and characterization of the Bambusa oldhamii BoMDH-encoded malate dehydrogenase. Protein Expr. Purif. 2020, 174, 105665. [CrossRef]

50. Hsu, W.-H.; Huang, Y.-H.; Chen, P.-R.; Hsieh, L.-S. NLIP and HAD-like domains of Pah1 and Lipin 1 phosphatidate phosphatases are essential for their catalytic activities. Molecules 2021, 26, 5470. [CrossRef]

51. De Jong, F.; Hanley, S.J.; Beale, M.H.; Karp, A. Characterization of the willow phenylalanine ammonia-lyase (PAL) gene family reveals expression differences compared with poplar. Phytochemistry 2015, 117, 90-97. [CrossRef] [PubMed]

52. Michaelis, L.; Menten, M.L. Die kinetik der invertinwirkung. Biochem. Z. 1913, 49, 333-369.

53. Lineweavwer, H.; Burk, D. The determination of enzyme dissociation constants. J. Am. Chem. Soc. 1934, 56, 658-666. [CrossRef] 